\title{
Specific Agrin Isoforms Induce cAMP Response Element Binding Protein Phosphorylation in Hippocampal Neurons
}

\author{
Ru-Rong Ji, Christian M. Böse, Christian Lesuisse, Dike Qiu, Justin C. Huang, Qin Zhang, and Fabio Rupp \\ Department of Neuroscience, School of Medicine, The Johns Hopkins University, Baltimore, Maryland 21205
}

The synaptic basal lamina protein agrin is essential for the formation of neuromuscular junctions. Agrin mediates the postsynaptic clustering of acetylcholine receptors and regulates transcription in muscles. Agrin expression is not restricted to motor neurons but can be demonstrated throughout the CNS. The functional significance of agrin expression in neurons other than motor neurons is unknown. To test whether agrin triggers responses in neurons that lead to the activation of transcription factors, we have analyzed phosphorylation of the transcriptional regulatory site serine 133 of the transcription factor CREB (cAMP response element binding protein) in primary hippocampal neurons. Our results indicate that the neuronal $(\mathrm{Ag} 4,8)$, but not the non-neuronal $(\mathrm{AgO}, 0)$, isoform of agrin induces CREB phosphorylation in hippocampal neurons. The kinetics of agrin- and BDNF-induced CREB phosphorylation are similar: peak levels are reached in minutes and are strongly reduced $2 \mathrm{hr}$ later. Neuronal responses to agrin require extracellular calcium, and, in contrast to tyrosine kinase inhibitors, the specific inhibition of protein kinase $A(P K A)$ does not affect agrin-evoked CREB phosphorylation. Our results show that hippocampal neurons specifically respond to neuronal agrin in a $\mathrm{Ca}^{2+}$-dependent manner and via the activation of tyrosine kinases.

Key words: agrin isoforms; CREB phosphorylation; hippocampal neurons; PKA; receptor tyrosine kinases; synapses; calcium
Many functional properties of synaptic transmission depend on the precise localization and stoichiometry of specialized molecules present on pre- and postsynaptic membranes. The high concentration of neurotransmitter receptors at postsynaptic sites is a general feature of synapses. The search for molecules able to regulate synaptic differentiation led to the discovery of agrin, an extracellular molecule capable of inducing the aggregation of acetylcholine receptors (AChR) on the surface of myotubes (McMahan, 1990; Burden, 1998). A critical role for agrin in the formation of neuromuscular junctions (NMJ) has been demonstrated in vitro and in vivo. Blocking the activity of neuronal agrin with specific antibodies in motor neuron/myotube cocultures prevents AChR aggregation at contact sites (Reist et al., 1992). Moreover, homologous recombination experiments revealed that agrin expression is essential for embryonic development and that NMJ do not form in homozygous agrin-deficient embryos (Gautam et al., 1996).

Agrin mediates AChR clustering in part via the activation of the receptor tyrosine kinase muscle-specific kinase (MuSK) (Jennings et al., 1993; Glass et al., 1996). MuSK phosphorylation in myotubes occurs rapidly after agrin addition, NMJ formation is similarly affected in MuSK-null mice and in agrin-deficient mice, and agrin does not induce AChR clustering in MuSK-deficient myotubes (DeChiara et al., 1996; Fuhrer et al., 1997; Hopf and Hoch, 1998).

The AChR-aggregating activity of agrin is regulated by alter-

\footnotetext{
Received June 18, 1998; revised Sept. 15, 1998; accepted Sept. 18, 1998.

This work was supported by National Institutes of Health (Grant MH51158) to F.R., the E. A. and J. Klingenstein Fund, the Council for Tobacco Research to F.R., and the Muscular Dystrophy Association. We thank David Ginty for the generous gift of brain-derived nerve growth factor. We are particularly thankful to David Ginty and Richard Huganir for critically reviewing this manuscript.

Correspondence should be addressed to Dr. Fabio Rupp at the above address.

Copyright (C) 1998 Society for Neuroscience $0270-6474 / 98 / 189695-08 \$ 05.00 / 0$
}

native splicing. Splicing at one particular location of the agrin mRNA, referred to as the $\mathrm{Z}$ position, produces isoforms that differ by $\sim 1000$-fold in their ability to cluster AChR on myotubes in vitro (Ferns et al., 1992, 1993; Ruegg et al., 1992; Rupp et al., 1992). The alternative splicing of agrin mRNA is regulated during development and is tissue-specific (Hoch et al., 1993; O’Connor et al., 1994; Ma et al., 1995; Stone and Nikolics, 1995; N. Cohen et al., 1997). Highly active agrin isoforms are found exclusively in neurons, whereas non-neuronal tissues, including muscle, express isoforms with low AChR-aggregating activity (Hoch et al., 1993; Ma et al., 1993; O’Connor et al., 1994; Stone and Nikolics, 1995; N. Cohen et al., 1997). Besides motor neurons, agrin is expressed in many different types of neurons throughout the CNS, including CA1 and CA3 pyramidal cells in the hippocampus and granule cells in the dentate gyrus, where agrin expression is regulated during development and by neuronal activity (O'Connor et al., 1995; N. Cohen et al., 1997). Despite its widespread expression in the nervous system, the role of agrin in neurons remains undetermined. Preliminary anatomical examination of agrin isoform-deficient mice does not reveal any gross abnormalities, suggesting that defective agrin expression does not compromise early aspects of neural development such as neurogenesis and axon guidance (Gautam et al., 1996). Although NMJ are absent in agrin-mutated mice, it is not known whether agrin mediates synapse formation in the CNS. Along with its effect in synapse formation, it has been proposed that agrin may function as a neural adhesion molecule and as a stop signal for sensory and motor neurons (Campagna et al., 1995; Chang et al., 1997; Martin and Sanes, 1997).

Recently, it has been shown that agrin induces specific changes of gene expression in muscle. Muscle and neuronal agrin increase the expression of utrophin in cultured myotubes, and agrin regulates the expression of AChR subunits in vivo (Jones et al., 1996; 
I. Cohen et al., 1997; Meier et al., 1997, 1998; Gramolini et al., 1998). Defective transcription in muscle fibers also has been observed in agrin-deficient mice (Gautam et al., 1996). To determine whether agrin isoforms induce specific responses in neurons that lead to the activation of transcription factors, we have analyzed the phosphorylation of the cAMP response element binding protein (CREB) in primary hippocampal neurons. CREB is a transcription factor that regulates gene expression in many cell types, including neurons (Ginty, 1997; Tamai et al., 1997). Phosphorylation of CREB at serine 133 is required for CREBmediated transcription (Ginty et al., 1993; Montminy, 1997). CREB can be phosphorylated via the activation of many kinases, including RSK2, a member of the pp90(RSK) family, protein kinase A (PKA), and $\mathrm{Ca}^{2+}$-calmodulin-dependent kinase IV (CaMK IV) (Sheng et al., 1991; Ginty et al., 1994; Xing et al., 1996; Montminy, 1997). Therefore, CREB phosphorylation is considered an integrative component of the cellular response underlying a variety of physiological processes (Tamai et al., 1997). In hippocampal neurons, for example, CREB phosphorylation is induced in response to trophic factors and by patterns of activity that lead to changes of synaptic efficacy (Bito et al., 1996; Deisseroth et al., 1996; Martin and Kandel, 1996). Our data show that specific agrin isoforms are able to induce CREB phosphorylation in hippocampal neurons, that this response requires extracellular calcium, and that it is mediated by tyrosine kinases.

\section{MATERIALS AND METHODS}

Primary cell cultures. Four to five hippocampi of 2- to 3-d-old Sprague Dawley rats were dissected rapidly ( $<40 \mathrm{~min})$. CA1-CA3 regions were isolated, sliced into four to five small pieces each, washed once in Hank's buffer, and incubated for 3-5 min at room temperature with trypsin (3 $\mathrm{mg} / \mathrm{ml}$ ) (Sigma, St. Louis, MO) and DNase $(0.6 \mathrm{mg} / \mathrm{ml})$ (Sigma) in digestion solution [containing (in mM) $137 \mathrm{NaCl}, 5 \mathrm{KCl}, 7 \mathrm{Na}_{2} \mathrm{HPO}_{4}, 25$ HEPES, and $4 \mathrm{NaHCO}_{3}, \mathrm{pH}$ 7.4). Tissues were dissociated by gentle pipetting in Hank's buffer supplemented with $0.3 \%$ BSA, $12 \mathrm{mM} \mathrm{MgSO}_{4}$, and $0.6 \mathrm{mg} / \mathrm{ml}$ DNase. Approximately 350,000 hippocampal neurons in 1 $\mathrm{ml}$ of Neurobasal medium (Life Technologies, Grand Island, NY) were cultured per well in 12-well plates precoated with poly-D-lysine. Arabino cytokine (5 $\mu \mathrm{m}$; Sigma) was added on the second day of culture.

Stimulation protocols. Agrin containing supernatant (conditioned media) were prepared as described (Ferns et al., 1993). The amounts of agrin isoforms in conditioned medium were normalized by Western blotting to standardized agrin quantities. Both the $\mathrm{Ag} 0,0$-conditioned and Ag4,8-conditioned media were used at 1:300 dilution, corresponding to $\sim 50 \mathrm{pM}$ agrin. Control medium from untransfected cells also was used at the same dilution. Ag4,8-conditioned medium (1:300) was tested for AChR clustering activity by using $\mathrm{C} 2$ myotubes as described (Ferns et al., 1993). Brain-derived neurotrophic factor (BDNF; kindly provided by Dr. David Ginty, Johns Hopkins University, Baltimore MD) was used at 40 $\mathrm{ng} / \mathrm{ml}$. Conditioned medium containing the $50 \mathrm{pm} \mathrm{Ag4,0}$ isoform was tested also. Various conditioned media and BDNF were added to hippocampal cultures for $10 \mathrm{~min}$. All pharmacological agents were added to the medium 20-30 min before stimulation. Cell morphology was evaluated after treatments; no alterations in processes and/or cell bodies were observed. TTX, CNQX, genistein, herbimycin A, forskolin, and Rp-8cAMP were purchased from Calbiochem (San Diego, CA); MK801 was purchased from RBI (Natick, MA).

Immunostaining. At $10 \mathrm{~min}$ after the stimulation the cells were fixed in $4 \%$ paraformaldehyde for $30 \mathrm{~min}$ and processed for immunocytochemistry according to the ABC method, as previously described (Ji and Rupp, 1997). Briefly, cultures were incubated with anti-pCREB (Polyclonal antibody, 1:2000; Upstate Biotechnology, Lake Placid, NY) at $4^{\circ} \mathrm{C}$ overnight. Then the cells were incubated with biotinylated secondary antibody and subsequently with $\mathrm{ABC}$ complex. The reaction product finally was visualized with $\mathrm{DAB} /$ hydrogen peroxide in acetate buffer containing ammonium nickel sulfate. Synaptophysin staining occurred as follows: cells were fixed in $4 \%$ paraformaldehyde $/ 4 \%$ sucrose for $30 \mathrm{~min}$ at $4^{\circ} \mathrm{C}$. Fixed cells were permeabilized in $1 \% \mathrm{BSA} / 0.4 \%$ saponin (Sigma) for $1 \mathrm{hr}$ at $4^{\circ} \mathrm{C}$. Synaptophysin-specific monoclonal antibody SY38
(Boehringer Mannheim, Indianapolis, IN) and FITC-conjugated goat anti-mouse antibodies (Jackson Laboratories, Bar Harbor, ME) were used as suggested by the manufacturers.

Western blot. Hippocampal cultures were lysed after treatment in 100 $\mu \mathrm{l}$ of boiling lysis buffer (100 mM Tris- $\mathrm{HCl}, \mathrm{pH} 6.8,20 \%$ glycerol, $2 \%$ SDS, $10 \%$ 2-mercaptoethanol, and $0.1 \%$ bromophenol blue) per well. Lysate $(20 \mu \mathrm{l})$ was loaded onto SDS-PAGE gradient gel $(4-15 \%$, BioRad Laboratories, Melville, NY) and transferred onto nitrocellulose filters. Filters were incubated with anti-pCREB antibodies (1:3000; Upstate Biotechnology) overnight at $4^{\circ} \mathrm{C}$. pCREB-immunoreactive bands were visualized via the ECL detection kit (Amersham, Arlington Heights, IL) and exposed onto X-ray films (XAR-5, Kodak, Rochester, NY) for 5-20 min. Subsequently, the blots were submerged in stripping solution (62.5 mM Tris-HCl, pH 6.7, 2\% SDS, and $100 \mathrm{~mm}$ 2-mercaptoethanol), incubated at $50^{\circ} \mathrm{C}$ for $30 \mathrm{~min}$, and probed with anti-CREB antiserum (1:2000; New England Biolabs, Beverly, MA) to detect the total level of CREB expression.

Quantification. pCREB-positive neurons were counted in each well. Counting was performed by a person unaware of the treatment protocol. Neurons with distinct nuclear staining, which were obviously different from the background, were counted as pCREB-positive. Five optic fields per $2.5 \mathrm{~cm}$ diameter well (one at the center and four at $\sim 0.5 \mathrm{~cm}$ from the edge of the well) were selected for counting at $20 \times$ magnification. The total number of neurons ranged from 70 to 230 per optic field. The percentage of pCREB-immunoreactive nuclei per optic field was calculated. The percentages of five fields were averaged as a mean, and four to six experiments in duplicate were included in each treatment. The data were assessed by an ANOVA test. The criterion for statistical significance was $p<0.05$.

\section{RESULTS}

\section{Agrin induces CREB phosphorylation in hippocampal neurons}

The 3-d-old primary neurons obtained from postnatal day 3 (P3) rat hippocampi were exposed to conditioned media containing an equal amount $(\sim 50 \mathrm{pm})$ of neuronal $(\mathrm{Ag} 4,8)$ and non-neuronal (Ag0,0) agrin isoforms. CREB phosphorylation at serine 133 (pCREB) was detected by using a specific polyclonal serum that recognizes CREB phosphorylated, but not CREB unphosphorylated (Ginty et al., 1993). pCREB immunoreactivity was analyzed by Western blotting with protein extracts prepared from hippocampal neurons incubated with agrin isoforms and compared with the response elicited by BDNF (40 ng/ml), a strong inducer of pCREB in neurons (Montminy, 1997). Exposure to Ag4,8 and $\mathrm{BDNF}$, but not to $\mathrm{Ag} 0,0$ or conditioned medium from untransfected COS cells, induced an increase in CREB phosphorylation (Fig. $1 A, B$ ). To quantify this response more precisely, we determined the number of pCREB-immunoreactive cells. A significant increase in the percentage of cell nuclei immunoreactive for pCREB, as compared with conditioned medium, was detected in cells exposed to $\mathrm{Ag} 4,8$ and BDNF, but not to $\mathrm{Ag} 0,0$ (82\% $p<$ $0.01,159 \% p<0.01$, and $-1.4 \% p>0.05$, respectively) (Fig. $2 B$ ). The pCREB response to both Ag4,8 and BDNF is transient, reaches its maximum within $10 \mathrm{~min}$, and has decreased significantly at $2 \mathrm{hr}$ (Fig. 2C). A larger number of hippocampal neurons respond to BDNF than to the Ag4,8 isoform.

Hippocampal neurons express many types of agrin isoforms, and secreted full-length agrin preferentially associates with the plasma membrane (Campanelli et al., 1991; O'Connor et al., 1995; N. Cohen et al., 1997). In motor neurons, agrin is secreted at axon terminals where it is incorporated into the synaptic basal lamina (Magill-Solc and McMahan, 1990; Reist et al., 1992). In fully differentiated NMJ both $\alpha$-dystroglycan, the major agrinbinding protein in muscle, and MuSK, a signaling component of the agrin receptor, are concentrated at synaptic sites (Hall and Sanes, 1993). This suggests the possibility that synapse formation may lead to a synaptic concentration of agrin, agrin-binding 


\section{A}

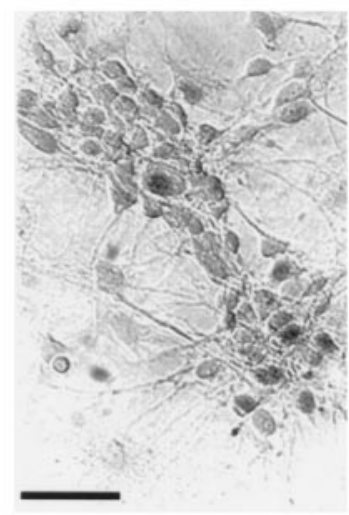

Control

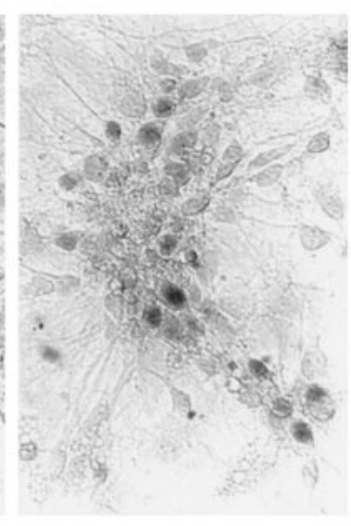

CM

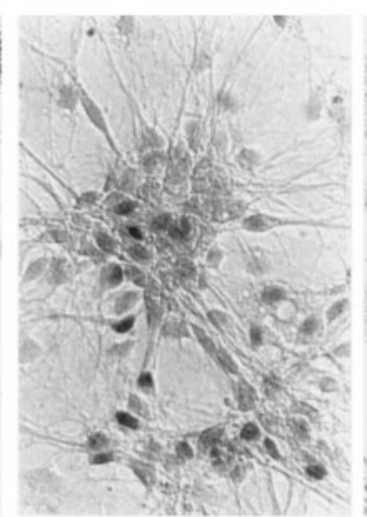

Ag0,0

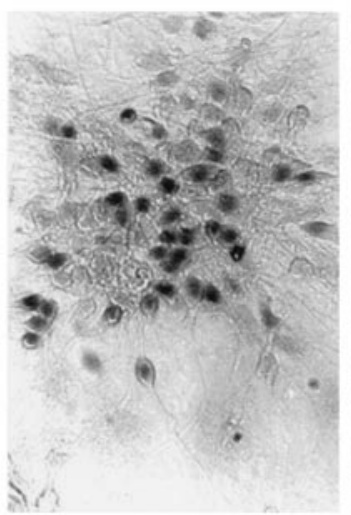

Ag4,8

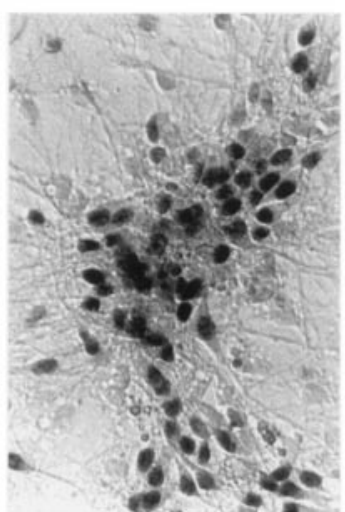

BDNF

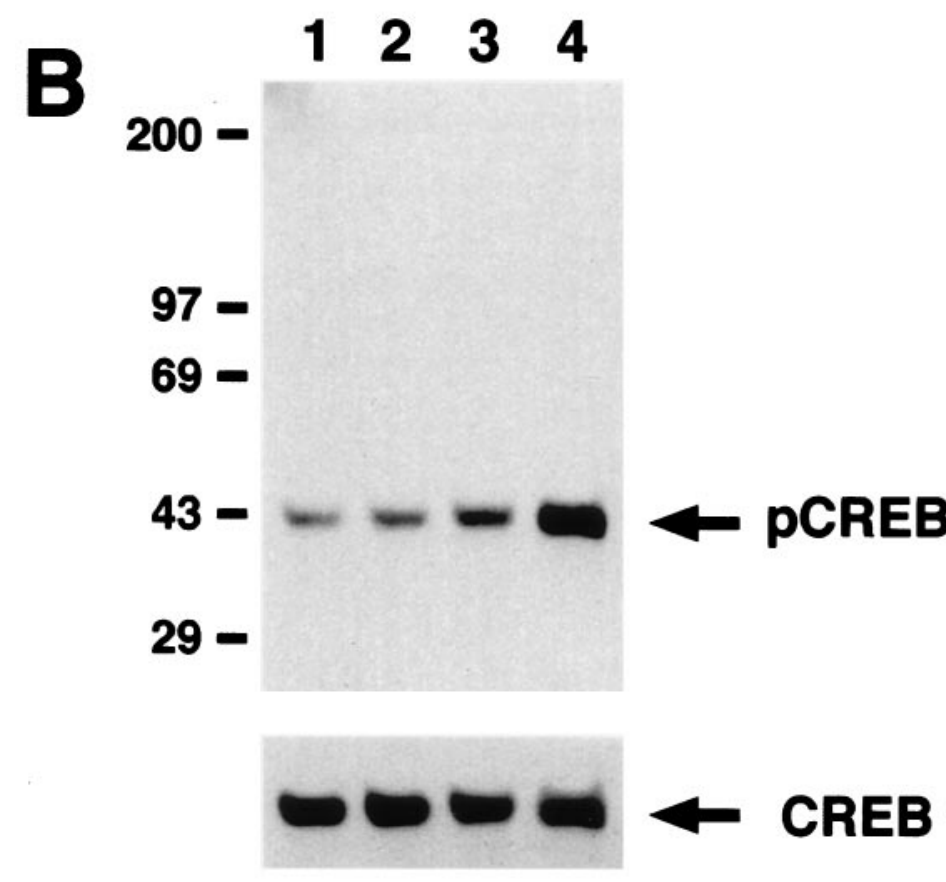

Figure 1. The neuronal agrin isoform $(A g 4,8)$, but not the nonneuronal isoform $(A g 0,0)$, can induce CREB phosphorylation ( $p C R E B)$ in P3-P5 hippocampal neurons. $A$, Detection of pCREB immunoreactivity in 3-d-old cultures. BDNF (40 ng/ml), the agrin isoforms $\mathrm{Ag} 0,0$ (50 pM) and $\mathrm{Ag} 4,8$ (50 pM), and conditioned medium from untransfected COS cells $(C M)$ were added for $10 \mathrm{~min}$. Cells were stained with the pCREB-specific antiserum. For illustration purposes, fields of particularly high cell density were chosen. Scale bar, $50 \mu \mathrm{m}$. B, Western blot analyses of 3-d-old P3-P5 hippocampal neurons. Neurons were incubated for $10 \mathrm{~min}$ with conditioned medium, $\mathrm{Ag} 0,0, \mathrm{Ag} 4,8$, and BDNF (lanes 1-4, respectively), and the extracts were probed with pCREB-specific antiserum (top panel). After the blots were stripped, they were probed with a CREB-specific antiserum to assess the total amount of CREB expression (bottom panel). proteins, and putative neuronal agrin receptors. To determine whether synapse formation affects the neuronal response to agrin in hippocampal neurons, we analyzed pCREB induction in 10-dold cultures. The formation of functional synapses in these cultures occurs after 6-7 d of plating (Banker and Goslin, 1988; Fletcher et al., 1994). Because of the different cellular densities used in these studies, we performed immunocytochemistry to determine the pattern of expression of the synaptic vesicle protein synaptophysin in 3- and 10-d-old cultures. The appearance of punctate synaptophysin immunoreactivity is used routinely as an indicator of synapse formation. Synaptophysin immunoreactivity in 3-d-old cultures predominantly is localized diffusely to the soma and throughout processes. A few immunoreactive puncta also can be detected. In contrast, in 10-d-old cultures the staining profile is different. The characteristic punctate pattern of synaptophysin immunoreactivity is evident on the soma and on neuritic processes (Fig. 2A). Similarly to neurons cultured for $3 \mathrm{~d}$ in which functional synaptic contacts are absent, a robust pCREB induction is observed with BDNF and $\mathrm{Ag} 4,8$, but not with $\mathrm{Ag} 0,0$ and control conditioned medium (Fig. 2B). The magnitude and the kinetics of the Ag4,8-induced and BDNF-induced CREB phosphorylation are similar among 3- and 10-d-old cultured neurons (data not shown). The $50 \mathrm{pm} \mathrm{Ag} 4,0$ isoform did not induce significant pCREB both in 3- and 10-d-old neurons $(1 \% p>0.05$ and $0.9 \% p>0.05$, respectively, as compared with control conditioned medium; $n=3$ ). These data show that hippocampal neurons selectively respond to the same highly active agrin isoforms as muscle fibers and that synapse formation does not affect the neuronal responses to agrin.

\section{Agrin-induced CREB phosphorylation depends on extracellular calcium}

Having established the ability of the $\mathrm{Ag} 4,8$ isoform to induce pCREB specifically in hippocampal neurons, we next examined the signaling pathways involved and whether this response is regulated similarly to the AChR clustering mediated by agrin at NMJ. The agrin-induced clustering of AChR on muscle fibers is dependent on extracellular $\mathrm{Ca}^{2+}$ (Henderson et al., 1984; Wal- 
A

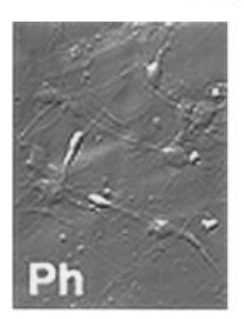

3 days

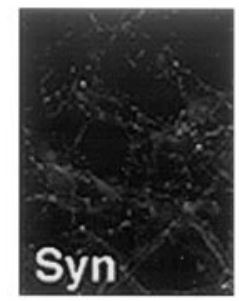

10 days

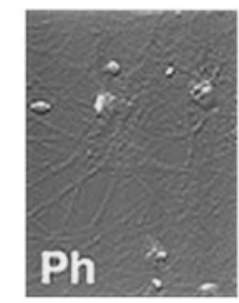

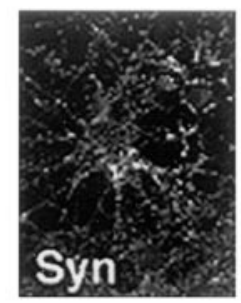

Figure 2. A, Profile of synaptophysin immunoreactivity in 3- and 10-d-old cultures. A shift from diffuse to punctate staining is observed between these two time points, indicating the absence and presence of synapses, respectively. Ph, Phase contrast, Syn, synaptophysin. B, Quantification of agrin-induced pCREB in 3- and 10-d-old cultures. The agrin isoform $\mathrm{Ag} 4,8$ and BDNF, but not $\mathrm{Ag} 0,0$, induce an increase in the percentage of pCREB-positive neurons both in 3 - and 10 -d-old cultures $(* * p<0.01$ as compared with control medium, ANOVA; $n=4)$. $C$, Agrin induces a transient increase in pCREBimmunoreactive cells. Incubation with $\mathrm{Ag} 4,8$ or BDNF was analyzed at $0,10,30$, and $120 \mathrm{~min}$, respectively. Both the $\mathrm{Ag} 4,8$ and BDNF responses reach a maximum within $10 \mathrm{~min}$ and are reduced within $2 \mathrm{hr}$. Despite the difference in magnitude, the BDNF- and Ag4,8-induced CREB phosphorylation essentially follows similar kinetics. $C M$, Control medium.
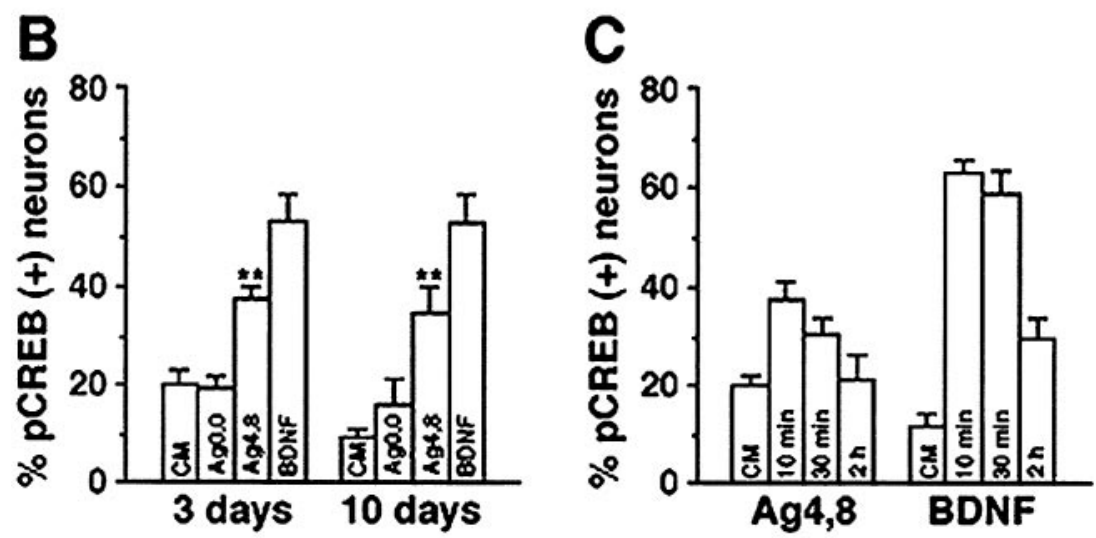

lace, 1988). To test the role of extracellular $\mathrm{Ca}^{2+}$ for the agrininduced induction of pCREB, we treated 3-d-old hippocampal neurons with the calcium chelator EGTA (4 mM) for $20 \mathrm{~min}$ before agrin treatment. EGTA pretreatment completely blocked pCREB induction by $\mathrm{Ag} 4,8$ but did not affect the BDNF response (Fig. $3 A, B)$. It has been shown previously that extracellular $\mathrm{Ca}^{2+}$ is not required for BDNF-induced CREB phosphorylation (Finkbeiner et al., 1997). Extracellular $\mathrm{Ca}^{2+}$ may be required for agrin binding to its receptor or may regulate $\mathrm{CREB}$ phosphorylation as a consequence of opening of $\mathrm{Ca}^{2+}$-permeable ion channels after depolarization (Ginty, 1997). Agrin may cause depolarization by mediating an acute release of glutamate in the media. To distinguish among these possibilities, we stimulated 3-d-old hippocampal neurons with $\mathrm{Ag} 4,8$ in the presence of the $\mathrm{Na}^{+}$channel blocker tetrodotoxin (TTX; $10 \mu \mathrm{M})$ or MK801 $(10 \mu \mathrm{M})$ and CNQX $(10 \mu \mathrm{M})$, which are specific antagonists of the NMDA and AMPA subfamilies of glutamate receptors, respectively. The presence of TTX or MK801 and CNQX in the medium partially reduces (21 and 23\%, respectively) agrin-induced pCREB (Fig. $3 C$ ). In all conditions, however, agrin did produce a significant increase of pCREB-positive cells ( 38 and $43 \%$, respectively). The magnitude of the agrin response was comparable when depolarization was prevented or glutamate receptors were blocked. The response to BDNF was not influenced by TTX or antagonists of glutamate receptors (Fig. $3 C$ ). These results demonstrate that the neuronal response to agrin requires extracellular $\mathrm{Ca}^{2+}$ and that a component of this response is partly attributable to the stimulation of glutamate release or increased receptor sensitization (see below).

\section{Agrin does not activate the PKA signaling pathway}

CREB phosphorylation can occur via the activation of cAMPdependent PKA after the induction of adenylyl cyclase activity and the subsequent rise of intracellular cAMP (Montminy, 1997). To test whether agrin activates this signaling pathway, we used the cyclic nucleotide analog Rp-8-CPT-cAMP, a specific PKA inhibitor, to test the involvement of PKA (Fig. 4). The efficiency of Rp-8-CPT-cAMP inhibition in 3-d-old hippocampal neurons was tested with forskolin, a PKA activator. As described previously, the application of forskolin $(75 \mu \mathrm{M})$ induces CREB phosphorylation (Gonzalez and Montminy, 1989). This response is inhibited significantly $(95 \%)$ by Rp-8-CPT-cAMP $(50 \mu \mathrm{M})$. In contrast, the Ag 4,8-induced and BDNF-induced responses are not affected significantly by Rp-8-CPT-cAMP, suggesting that agrin-induced pCREB in hippocampal neurons does not result from the activation of PKA.

\section{Agrin-induced CREB phosphorylation in neurons is regulated by tyrosine kinases}

Activation of the receptor tyrosine kinases is required to induce AChR clustering at NMJ (Peng et al., 1993; Wallace, 1994; DeChiara et al., 1996; Ferns et al., 1996; Glass et al., 1996, 1997; Hopf and Hoch, 1998). To investigate the dependency of the agrin-induced phosphorylation of CREB on the activity of tyrosine kinases, we incubated 3-d-old hippocampal neurons with the specific protein tyrosine kinase inhibitors genistein and herbimycin A. Pretreatment (20 min) with either genistein $(100 \mu \mathrm{M})$ or herbimycin A $(1.5 \mu \mathrm{M})$ resulted in an inhibition of the $\mathrm{Ag} 4,8$ and BDNF-induced pCREB (Fig. 5). Genistein treatments equally affected the agrin- and the BDNF-induced responses by 71 and $69 \%$ inhibition, respectively. Herbimycin A was more effective in suppressing the agrin-induced pCREB (92\%) than the BDNF-induced one (55\%). No morphological changes could be observed in treated cells, suggesting that short-time exposure (30 min) with these inhibitors did not affect the hippocampal neurons adversely.

\section{DISCUSSION}

Agrin induces a response in hippocampal neurons that leads to the phosphorylation of the transcription factor CREB. Several parameters tested in this study indicate that the neuronal re- 
A

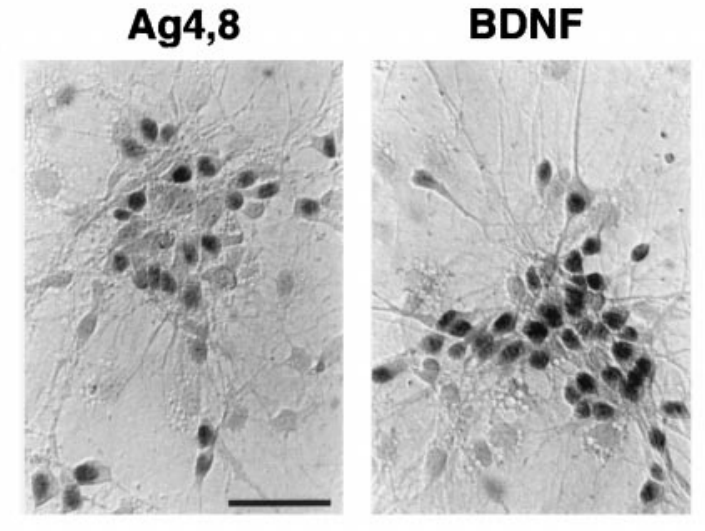

- EGTA
Ag 4,8

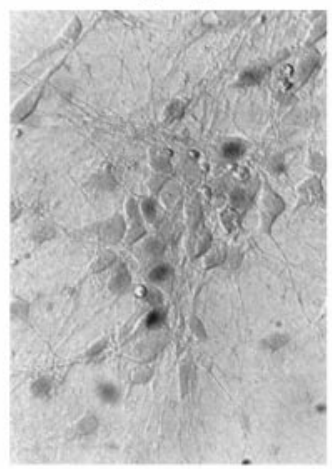

BDNF

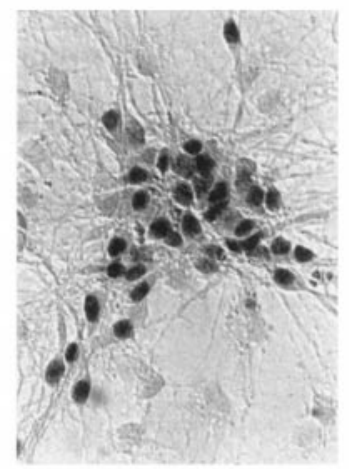

EGTA
B

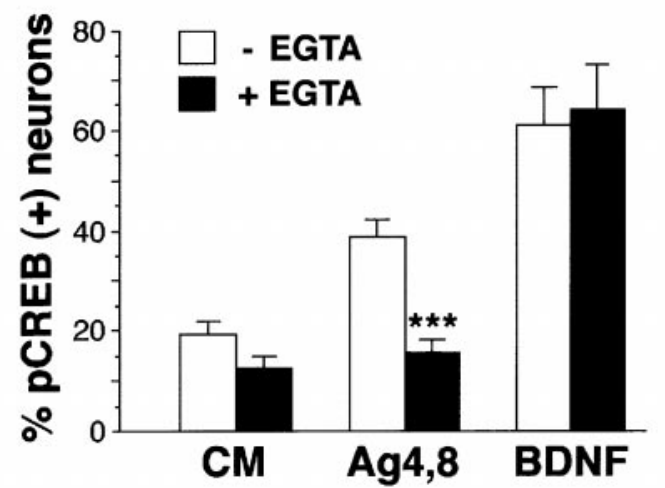

C

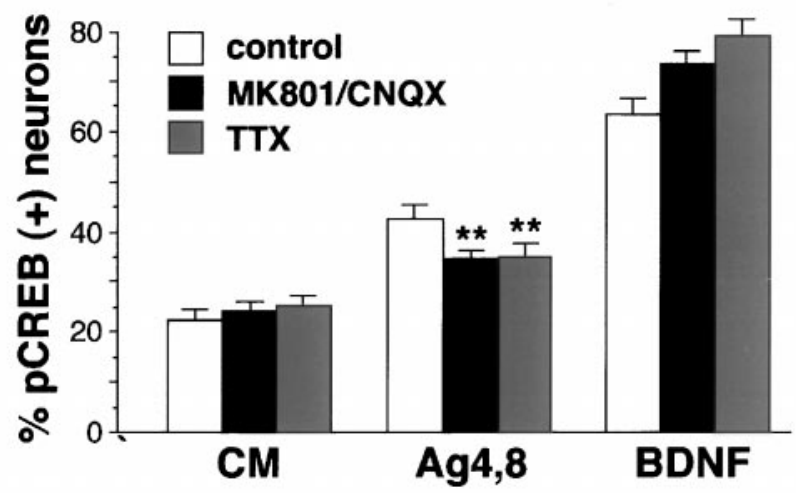

Figure 3. Agrin-induced pCREB in hippocampal neurons depends on extracellular $\mathrm{Ca}^{2+} . A, B$, Agrin-induced pCREB is inhibited significantly by EGTA $(4 \mathrm{~mm}) .{ }^{* * *} p<0.001$, ANOVA $(n=4)$, as compared with agrin response without EGTA. The BDNF-induced pCREB is not affected. $C$, Preventing depolarization and blocking glutamate receptors partially reduce agrin responses in hippocampal neurons. The pCREB-positive neurons induced by agrin in the presence of TTX or a combination of the NMDA receptor antagonist dizocilpine maleate $(M K-801)(10 \mu \mathrm{M})$ and the non-NMDA antagonist 6-cyano-7-nitroquinoxaline-2,3-dione $(C N Q X)(10 \mu \mathrm{M})$ are reduced by $21 \%(p<0.05$, ANOVA; $n=5)$ and $23 \%(p<0.05$, ANOVA; $n=$ $4)$, respectively, when compared with the agrin response. However, a comparison between responses to agrin and conditioned medium in the presence of TTX or glutamate receptor antagonists still shows a significant increase in pCREB-positive cells of $38 \%(* * p<0.01$, ANOVA; $n=5)$ and $48 \%(* * p<$ 0.01 , ANOVA; $n=4)$, respectively. Scale bar, $50 \mu \mathrm{m}$.

sponse to agrin and the agrin-induced aggregation of the AChR at NMJ are regulated similarly. In particular, only the agrin isoforms with the highest AChR clustering activity $(\mathrm{Ag} 4,8)$, but not the ones with low activity $(\mathrm{Ag} 0,0)$, induce pCREB in hippocampal neurons. Another similarity is the role that tyrosine kinases play in mediating agrin responses in muscle and neurons. The role of the receptor tyrosine kinase MuSK in myotubes is well defined (Peng et al., 1993; Wallace, 1994; DeChiara et al., 1996; Ferns et al., 1996; Glass et al., 1996, 1997; Hopf and Hoch, 1998). One of the early events in AChR clustering is the binding of agrin to MuSK, which becomes phosphorylated at tyrosine residues within minutes of agrin addition (Glass et al., 1996). Other phosphorylation events downstream of the initial activation of MuSK also occur. Tyrosine phosphorylation of the $\beta$-subunit of the AChR is concomitant to AChR clustering, but it does not seem to be necessary for this process (Wallace et al., 1991; Swope et al., 1995; Ferns et al., 1996). We have demonstrated that, as in myotubes, the activation of tyrosine kinases is an essential step in the signaling cascade activated by agrin in neurons.

There is a similar requirement for extracellular $\mathrm{Ca}^{2+}$ for agrin function in neurons and muscle. Extracellular $\mathrm{Ca}^{2+}$ is required for both agrin-induced CREB phosphorylation in hippocampal neurons and for the agrin-induced aggregation of AChR on myotubes. There are two possible explanations for the $\mathrm{Ca}^{2+}$ dependence in muscle. $\mathrm{Ca}^{2+}$ may influence the binding of agrin to its receptor; it has been reported that in the absence of $\mathrm{Ca}^{2+}$ agrin does not bind to the myotube surface (Nastuk et al., 1991; Ma et al., 1993; Gee et al., 1994). Alternatively, engagement of the agrin receptor may trigger a signaling cascade that leads to $\mathrm{Ca}^{2+}$ influx. Because the addition of neither the AChR antagonist $\alpha$-bungarotoxin nor the $\mathrm{Na}^{+}$channel blocker tetrodotoxin affects agrin-induced AChR aggregation, neither AChR activation nor $\mathrm{Na}^{+}$channel-dependent depolarization must be required for $\mathrm{Ca}^{2+}$ influx into muscle fibers (Anderson et al., 1977; Godfrey et al., 1988). A role for a transient rise of intracellular $\mathrm{Ca}^{2+}$ concentration has been proposed recently for agrininduced AChR clustering (Mook-Jung and Gordon, 1995; Megeath and Fallon, 1998). However, the precise source responsible for these intracellular calcium transients remains undetermined. There are other possible roles for $\mathrm{Ca}^{2+}$ in the neural 

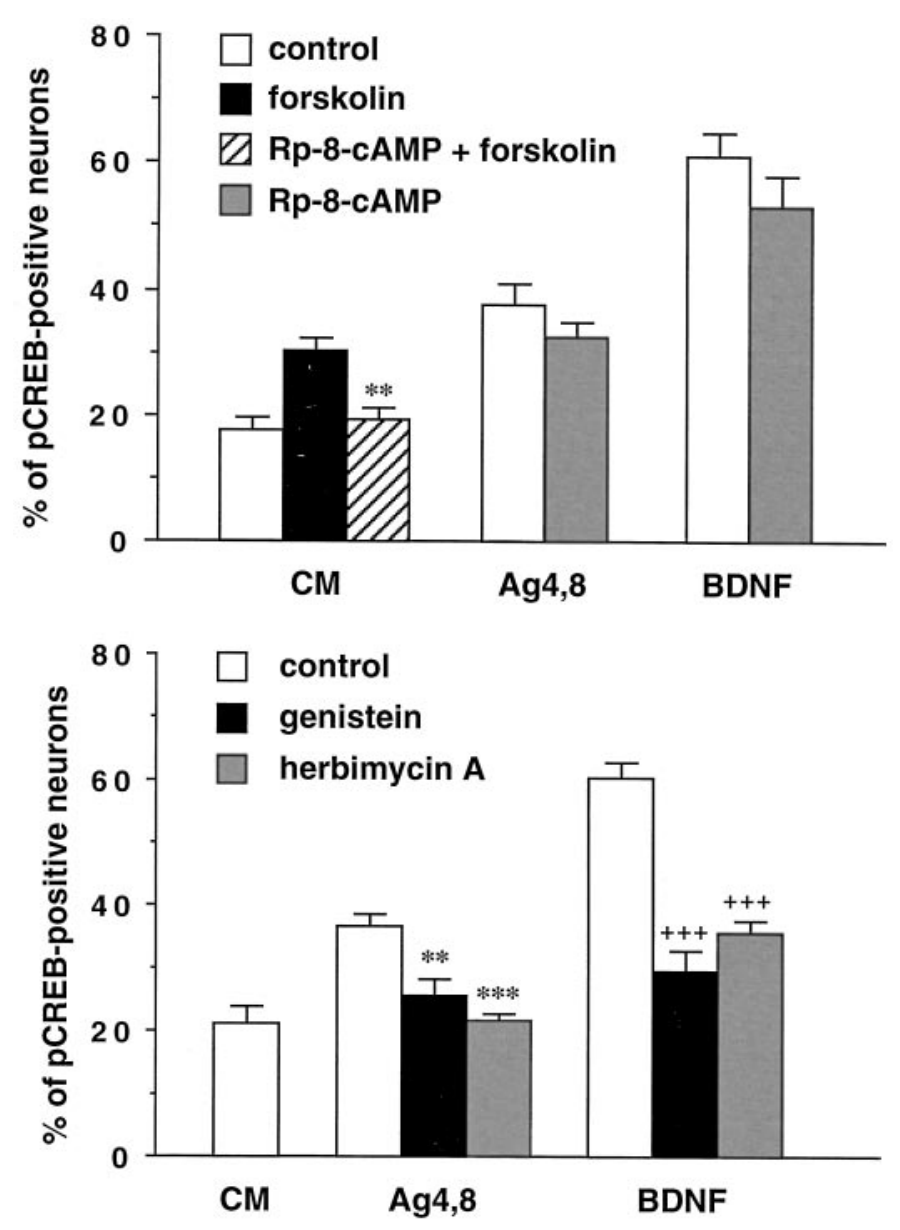

Figure 4. Top. Agrin does not activate the PKA signaling pathway. The specific PKA inhibitor Rp-8-CPT-cAMP $(50 \mu \mathrm{M})$ does not affect the agrin- and the BDNF-induced pCREB. However, Rp-8-CPT-cAMP greatly inhibits $(95 \%)$ pCREB induced by the PKA activator forskolin (75 $\mu \mathrm{M}) ;{ }^{*} p<0.01$, ANOVA; $n=5$.

Figure 5. Bottom. Agrin-induced pCREB is inhibited significantly by tyrosine kinase inhibitors. The protein tyrosine kinase inhibitors genistein $(100 \mu \mathrm{M})$ and herbimycin A $(1.5 \mu \mathrm{M})$ greatly reduce the agrinand the BDNF-induced CREB phosphorylation in day 3 hippocampal neurons. ${ }^{* *} p<0.01,{ }^{* * *} p<0.001$, ANOVA; $n=4$, as compared with agrin induction. ${ }^{++} p<0.001$, ANOVA; $n=4$, as compared with BDNF.

response to agrin. Again, a $\mathrm{Ca}^{2+}$ requirement for agrin binding to its receptor(s) or voltage-gated $\mathrm{Ca}^{2+}$ channels activation may be involved. In neurons, however, the addition of TTX or glutamate receptor antagonists reduces the magnitude of the agrin response even before the establishment of functional synapses. This suggests that a component of the neuronal response to agrin is attributable to acute release of glutamate and/or increased glutamate responsivity. Both cases would result in $\mathrm{Na}^{+}$channeldependent depolarization, which would activate voltage-gated $\mathrm{Ca}^{2+}$ channels. How could agrin stimulate neurotransmitter release? It has been reported that agrin promotes the differentiation of presynaptic specializations in motor neurons (Campagna et al., 1997). It is possible that an acute exposure to agrin may affect the proteins involved in synaptic vesicle release, thus favoring the fusion of vesicles that are docked either along, or in the proximity of, the plasma membrane of growth cones. Alternatively, agrin may change the cellular responses to glutamate. This may occur via sensitization of glutamate receptors, possibly via posttranslational modifications, or via stimulation of receptor insertion in the plasma membrane, as proposed for silent synapses (Malenka and Nicoll, 1997).

Our results show that the neuronal response to agrin is unaffected by synapse formation. Both the background levels and the magnitude of agrin-induced CREB phosphorylation are comparable in neurons before or after functional synapses are formed. This suggests that endogenous agrin does not saturate agrin receptors and that desensitization of the receptors occurs. Neuronal agrin receptors may aggregate partially at synaptic sites, or they may not aggregate at all. This also may explain the persistent neuronal response to exogenously applied agrin. Alternatively, agrin expression may decrease after synapse formation to levels that are no longer able to trigger a response. This hypothesis is consistent with results showing that agrin expression decreases at developmental times concomitant with synapse formation in vivo (Rupp et al., 1991; Thomas et al., 1993; Stone and Nikolics, 1995; N. Cohen et al., 1997; Li et al., 1997) and that a similar regulation of agrin expression is observed in vitro (Li et al., 1997). Last, agrin may not be required for synapse formation in hippocampal neurons but may function as an adhesion molecule. This hypothesis is supported by data showing that sensory and motor neurons adhere to agrin and that, in muscle, integrins also can function as an additional agrin receptor (Chang et al., 1997; Martin and Sanes, 1997). Whether agrin can induce the activation of receptors for adhesion molecules in hippocampal neurons has not yet been determined.

Finally, it has been shown that CREB phosphorylation in hippocampal neurons plays an important role in the regulation of gene expression, including the $\mathrm{Ca}^{2+}$-dependent activation of transcription, which is thought to underlie long-term changes of synapse strength (Deisseroth et al., 1996; Ginty, 1997). Our data, along with results showing that agrin expression in neurons is regulated by synapse formation and by electrical activity (O’Connor et al., 1995; N. Cohen et al., 1997; Li et al., 1997), are consistent with the hypothesis that agrin may play a role in the regulation of synaptic efficacy. Taken together, our data support the hypothesis that hippocampal neurons and muscle fibers express agrin receptor(s) with the same specificity for agrin isoforms and that the receptor expressed in neurons is likely to be a novel member of the receptor tyrosine kinase family, because MuSK expression is confined to muscle and spleen (Jennings et al., 1993; Glass et al., 1996).

\section{REFERENCES}

Anderson MJ, Cohen MW, Zorychta E (1977) Effects of innervation on the distribution of acetylcholine receptors on cultured muscle cells. J Physiol (Lond) 268:731-756.

Banker G, Goslin K (1988) Developments in neuronal cell culture. Nature 336:185-186.

Bito H, Deisseroth K, Tsien RW (1996) CREB phosphorylation and dephosphorylation: a $\mathrm{Ca}^{2+}$ - and stimulus duration-dependent switch for hippocampal gene expression. Cell 87:1203-1214.

Burden SJ (1998) The formation of neuromuscular synapses. Genes Dev $12: 133-148$

Campagna JA, Ruegg MA, Bixby JL (1995) Agrin is a differentiationinducing "stop-signal" for motor neurons in vitro. Neuron 15:1365-1374.

Campagna JA, Ruegg MA, Bixby JL (1997) Evidence that agrin directly influences presynaptic differentiation at neuromuscular junctions in vitro. Eur J Neurosci 9:2269-2283. 
Campanelli JT, Hoch W, Rupp F, Kreiner T, Scheller RH (1991) Agrin mediates cell contact-induced acetylcholine receptor clustering. Cell 67:909-916.

Chang D, Woo JS, Campanelli J, Scheller RH, Ignatius MJ (1997) Agrin inhibits neurite outgrowth but promotes attachment of embryonic motor and sensory neurons. Dev Biol 181:21-35.

Cohen I, Rimer M, Lomo T, McMahan UJ (1997) Agrin-induced postsynaptic-like apparatus in skeletal muscle fibers in vivo. Mol Cell Neurosci 9:237-253.

Cohen NA, Kaufmann WE, Worley PF, Rupp F (1997) Expression of agrin in the developing and adult rat brain. Neuroscience 76:581-596.

DeChiara TM, Bowen DC, Valenzuela DM, Simmons MV, Poueymirou WT, Thomas S, Kinetz E, Compton DL, Rojas E, Park JS, Smith C, DiStefano PS, Glass DJ, Burden SJ, Yancopoulos GD (1996) The receptor tyrosine kinase MuSK is required for neuromuscular junction formation in vivo. Cell 85:501-512.

Deisseroth K, Bito H, Tsien RW (1996) Signaling from synapse to nucleus: postsynaptic CREB phosphorylation during multiple forms of hippocampal synaptic plasticity. Neuron 16:89-101.

Ferns M, Hoch W, Campanelli JT, Rupp F, Hall ZW, Scheller RH (1992) RNA splicing regulates agrin-mediated acetylcholine receptor clustering activity on cultured myotubes. Neuron 8:1079-1086.

Ferns M, Campanelli JT, Hoch W, Scheller RH, Hall Z (1993) The ability of agrin to cluster AChRs depends on alternative splicing and on cell surface proteoglycans. Neuron 11:491-502.

Ferns M, Deiner M, Hall Z (1996) Agrin-induced acetylcholine receptor clustering in mammalian muscle requires tyrosine phosphorylation. J Cell Biol 132:937-944.

Finkbeiner S, Tavazoie SF, Maloratsky A, Jacobs KM, Harris KM, Greenberg ME (1997) CREB: a major mediator of neuronal neurotrophin responses. Neuron 19:1031-1047.

Fletcher TL, De Camilli P, Banker G (1994) Synaptogenesis in hippocampal cultures: evidence indicating that axons and dendrites become competent to form synapses at different stages of neuronal development. J Neurosci 14:6695-6706.

Fuhrer C, Sugiyama JE, Taylor RG, Hall ZW (1997) Association of muscle-specific kinase MuSK with the acetylcholine receptor in mammalian muscle. EMBO J 16:4951-4960.

Gautam M, Noakes PG, Moscoso L, Rupp F, Scheller RH, Merlie JP, Sanes JR (1996) Defective neuromuscular synaptogenesis in agrindeficient mutant mice. Cell 85:525-535.

Gee SH, Montanaro F, Lindenbaum MH, Carbonetto S (1994) Dystroglycan- $\alpha$, a dystrophin-associated glycoprotein, is a functional agrin receptor. Cell 77:675-686.

Ginty DD (1997) Calcium regulation of gene expression: isn't that spatial? Neuron 18:183-186.

Ginty DD, Kornhauser JM, Thompson MA, Bading H, Mayo KE, Takahashi JS, Greenberg ME (1993) Regulation of CREB phosphorylation in the suprachiasmatic nucleus by light and a circadian clock. Science 260:238-241.

Ginty DD, Bonni A, Greenberg ME (1994) Nerve growth factor activates a Ras-dependent protein kinase that stimulates $\mathrm{c}$-fos transcription via phosphorylation of CREB. Cell 77:713-725.

Glass DJ, Bowen DC, Stitt TN, Radziejewski C, Bruno J, Ryan TE, Gies DR, Shah S, Mattsson K, Burden SJ, Distefano PS, Valenzuela DM, Dechiara TM, Yancopoulos GD (1996) Agrin acts via a MuSK receptor complex. Cell 85:513-523.

Glass DJ, Apel ED, Shah S, Bowen DC, DeChiara TM, Stitt TN, Sanes JR, Yancopoulos GD (1997) Kinase domain of the muscle-specific receptor tyrosine kinase (MuSK) is sufficient for phosphorylation but not clustering of acetylcholine receptors: required role for the MuSK ectodomain? Proc Natl Acad Sci USA 94:8848-8853.

Godfrey EW, Siebenlist RE, Wallskog PA, Walters LM, Bolender DL, Yorde DE (1988) Basal lamina components are concentrated in premuscle masses and at early acetylcholine receptor clusters in chick embryo hindlimb muscles. Dev Biol 130:471-486.

Gonzalez GA, Montminy MR (1989) Cyclic AMP stimulates somatostatin gene transcription by phosphorylation of CREB at serine 133. Cell 59:675-680.

Gramolini AO, Burton EA, Tinsley JM, Ferns MJ, Cartaud A, Cartaud J, Davies KE, Lunde JA, Jasmin BJ (1998) Muscle and neural isoforms of agrin increase utrophin expression in cultured myotubes via a transcriptional regulatory mechanism. J Biol Chem 273:736-743.

Hall ZW, Sanes JR (1993) Synaptic structure and development: the neuromuscular junction. Cell 72:99-121.
Henderson LP, Smith MA, Spitzer NC (1984) The absence of calcium blocks impulse-evoked release of acetylcholine but not de novo formation of functional neuromuscular synaptic contacts in culture. J Neurosci 4:3140-3150.

Hoch W, Ferns M, Campanelli JT, Hall ZW, Scheller RH (1993) Developmental regulation of highly active alternatively spliced forms of agrin. Neuron 11:479-490.

Hopf C, Hoch W (1998) Dimerization of the muscle-specific kinase induces tyrosine phosphorylation of acetylcholine receptors and their aggregation on the surface of myotubes. J Biol Chem 273:6467-6473.

Jennings CG, Dyer SM, Burden SJ (1993) Muscle-specific trk-related receptor with a kringle domain defines a distinct class of receptor tyrosine kinases. Proc Natl Acad Sci USA 90:2895-2899.

Ji RR, Rupp F (1997) Phosphorylation of transcription factor CREB in rat spinal cord after formalin-induced hyperalgesia: relationship to c-fos induction. J Neurosci 17:1776-1785.

Jones G, Herczeg A, Ruegg MA, Lichtsteiner M, Kroger S, Brenner HR (1996) Substrate-bound agrin induces expression of acetylcholine receptor $\epsilon$-subunit gene in cultured mammalian muscle cells. Proc Natl Acad Sci USA 93:5985-5990.

Li Z, Massengill JL, O’Dowd DK, Smith MA (1997) Agrin gene expression in mouse somatosensory cortical neurons during development in vivo and in cell culture. Neuroscience 79:191-201.

Ma E, Morgan R, Godfrey EW (1995) Agrin mRNA variants are differentially regulated in developing chick embryo spinal cord and sensory ganglia. J Neurobiol 26:585-597.

Ma J, Nastuk MA, McKechnie BA, Fallon JR (1993) The agrin receptor. Localization in the postsynaptic membrane, interaction with agrin, and relationship to the acetylcholine receptor. J Biol Chem 268:25108-25117.

Magill-Solc C, McMahan UJ (1990) Synthesis and transport of agrin-like molecules in motor neurons. J Exp Biol 153:1-10.

Malenka RC, Nicoll RA (1997) Silent synapses speak up. Neuron 19:473-476.

Martin KC, Kandel ER (1996) Cell adhesion molecules, CREB, and the formation of new synaptic connections. Neuron 17:567-570.

Martin PT, Sanes JR (1997) Integrins mediate adhesion to agrin and modulate agrin signaling. Development 124:3909-3917.

McMahan UJ (1990) The agrin hypothesis [review]. Cold Spring Harb Symp Quant Biol 55:407-418.

Megeath LJ, Fallon JR (1998) Intracellular calcium regulates agrininduced acetylcholine receptor clustering. J Neurosci 18:672-678.

Meier T, Hauser DM, Chiquet M, Landmann L, Ruegg MA, Brenner HR (1997) Neural agrin induces ectopic postsynaptic specializations in innervated muscle fibers. J Neurosci 17:6534-6544.

Meier T, Masciulli F, Moore C, Schoumacher F, Eppenberger U, Denzer AJ, Jones G, Brenner HR (1998) Agrin can mediate acetylcholine receptor gene expression in muscle by aggregation of muscle-derived neuregulins. J Cell Biol 141:715-726.

Montminy M (1997) Transcriptional regulation by cyclic AMP. Annu Rev Biochem 66:807-822.

Mook-Jung I, Gordon H (1995) Acetylcholine receptor clustering in C2 muscle cells requires chondroitin sulfate. J Neurobiol 28:482-492.

Nastuk MA, Lieth E, Ma JY, Cardasis CA, Moynihan EB, McKechnie BA, Fallon JR (1991) The putative agrin receptor binds ligand in a calcium-dependent manner and aggregates during agrin-induced acetylcholine receptor clustering. Neuron 7:807-818.

O'Connor LT, Lauterborn JC, Gall CM, Smith MA (1994) Localization and alternative splicing of agrin mRNA in adult rat brain: transcripts encoding isoforms that aggregate acetylcholine receptors are not restricted to cholinergic regions. J Neurosci 14:1141-1152.

O'Connor LT, Lauterborn JC, Smith MA, Gall CM (1995) Expression of agrin mRNA is altered following seizures in adult rat brain. Brain Res Mol Brain Res 33:277-287.

Peng HB, Baker LP, Dai Z (1993) A role of tyrosine phosphorylation in the formation of acetylcholine receptor clusters induced by electric fields in cultured Xenopus muscle cells. J Cell Biol 120:197-204.

Reist NE, Werle MJ, McMahan UJ (1992) Agrin released by motor neurons induces the aggregation of acetylcholine receptors at neuromuscular junctions. Neuron 8:865-868.

Ruegg MA, Tsim KW, Horton SE, Kroger S, Escher G, Gensch EM, McMahan UJ (1992) The agrin gene codes for a family of basal lamina proteins that differ in function and distribution. Neuron 8:691-699. 
Rupp F, Payan DG, Magill-Solc C, Cowan DM, Scheller RH (1991) Structure and expression of a rat agrin. Neuron 6:811-823.

Rupp F, Ozcelik T, Linial M, Peterson K, Francke U, Scheller R (1992) Structure and chromosomal localization of the mammalian agrin gene. J Neurosci 12:3535-3544.

Sheng M, Thompson MA, Greenberg ME (1991) CREB: a $\mathrm{Ca}^{2+}$ regulated transcription factor phosphorylated by calmodulindependent kinases. Science 252:1427-1430.

Stone DM, Nikolics K (1995) Tissue- and age-specific expression patterns of alternatively spliced agrin mRNA transcripts in embryonic rat suggest novel developmental roles. J Neurosci 15:6767-6778.

Swope SL, Qu Z, Huganir RL (1995) Phosphorylation of the nicotinic acetylcholine receptor by protein tyrosine kinases. Ann NY Acad Sci 757:197-214
Tamai KT, Monaco L, Nantel F, Zazopoulos E, Sassone-Corsi P (1997) Coupling signaling pathways to transcriptional control: nuclear factors responsive to cAMP. Recent Prog Horm Res 52:121-139.

Thomas WS, O'Dowd DK, Smith MA (1993) Developmental expression and alternative splicing of chick agrin RNA. Dev Biol 158:523-535.

Wallace BG (1988) Regulation of agrin-induced acetylcholine receptor aggregation by $\mathrm{Ca}^{2+}$ and phorbol ester. J Cell Biol 107:267-278.

Wallace BG (1994) Staurosporine inhibits agrin-induced acetylcholine receptor phosphorylation and aggregation. J Cell Biol 125:661-668.

Wallace BG, Qu Z, Huganir RL (1991) Agrin induces phosphorylation of the nicotinic acetylcholine receptor. Neuron 6:869-878.

Xing J, Ginty DD, Greenberg ME (1996) Coupling of the RAS-MAPK pathway to gene activation by RSK2, a growth factor-regulated CREB kinase. Science 273:959-963. 